\title{
Antimalarial Activities of Alkyl Cyclohexenone Derivatives Isolated from the Leaves of Poupartia borbonica
}

\author{
Allison Ledoux, ${ }^{*}{ }^{\dagger} \odot$ Alexis St-Gelais, ${ }^{\dagger, \S}$ Ewa Cieckiewicz, ${ }^{\dagger}$ Olivia Jansen, ${ }^{\dagger}$ Annélise Bordignon, ${ }^{\dagger}$ \\ Bertrand Illien, ${ }^{\perp}$ Nicolas Di Giovanni, $"$ Arnaud Marvilliers, ${ }^{\perp}$ Floriane Hoareau, ${ }^{\perp}$ Hélène Pendeville, ${ }^{\nabla}$ \\ Joëlle Quetin-Leclercq, ${ }^{\ddagger}$ and Michel Frédérich ${ }^{\dagger}$ \\ ${ }^{\dagger}$ Laboratory of Pharmacognosy, Center for Interdisciplinary Research on Medicines (CIRM), University of Liège, Avenue Hippocrate \\ 15, 4000 Liège, Belgium \\ ${ }^{\ddagger}$ Pharmacognosy Research Group, Louvain Drug Research Institute, Université Catholique de Louvain, Avenue E. Mounier, B1 72.03, \\ B-1200 Brussels, Belgium \\ ${ }^{\S}$ Laboratoire d'Analyses et de Séparation des Essences Végétales (LASEVE), Université du Québec à Chicoutimi, 555 Boulevard de \\ l'Université, Saguenay, Québec G7H 2B1, Canada \\ ${ }^{\perp}$ Laboratoire de Chimie des Substances Naturelles et des Sciences des Aliments (LCSNA), University of Reunion Island, Avenue \\ René Cassin 15, 97744 Saint-Denis, La Réunion France \\ "Laboratoire de Chimie Analytique Organique et Biologique (OBiAChem), University of Liège, Allée de la Chimie 3, Sart-Tilman, \\ 4000 Liège, Belgium \\ ${ }^{\nabla}$ Plateforme Zebrafish Facility and Transgenics, GIGA, University of Liège, Avenue Hippocrate 15, 4000 Liège, Belgium
}

\section{Supporting Information}

\begin{abstract}
Bioactivity-guided fractionation of the ethyl acetate extract of the leaves of Poupartia borbonica led to the isolation of three new alkyl cyclohexenone derivatives 1-3, and named Poupartone A-C. The structures of the new compounds were elucidated by $1 \mathrm{D}$ and $2 \mathrm{D}$ NMR spectroscopic data analysis and MS, whereas calculated and experimental ECD spectra were used to define the absolute configurations. These compounds were active against 3D7 and W2 Plasmodium falciparum strains with $\mathrm{IC}_{50}$ values between 0.55 and $1.81 \mu \mathrm{M}$. In vitro cytotoxicity against WI38 human fibroblasts and the human cervical cancer cell line HeLa (WST-1 assay) showed that these compounds were also cytotoxic, but no hemolytic activity was observed for the extract and pure compounds. An in vivo antimalarial assay was performed on the major cyclohexenone using $P$. berghei-infected mice at a dose of $15 \mathrm{mg} / \mathrm{kg} /$ day ip. The assay revealed growth inhibition of 59.1 and $69.5 \%$ at days 5 and 7 postinfection, respectively, although some toxicity was observed. Zebrafish larvae were used as a model to determine the type of toxicity, and the results showed cardiac toxicity. The methanol extract was also studied, and it displayed moderate antiplasmodial properties in vitro. This extract contained the known flavonoids, quercetin, 3 - $-O$-hydroxysulfonylquercetin, quercitrin, and isoquercitrin as well as ellagic acid, which showed high to low activity against the 3D7 P. falciparum strain.

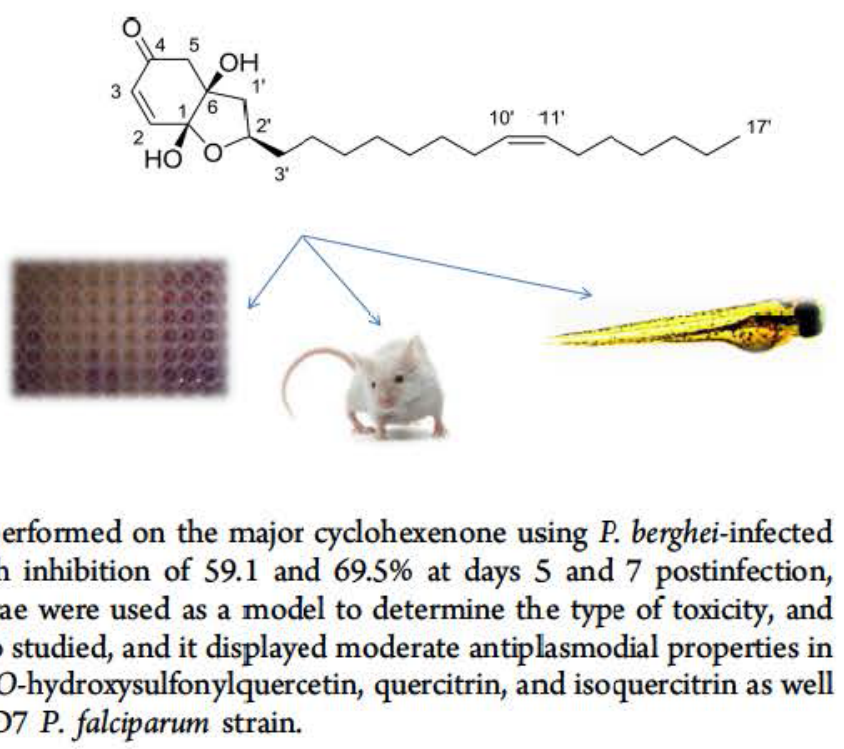

\begin{abstract}
$\mathrm{M}$ alaria is caused by Plasmodium, a protozoan parasite transmitted by anopheles mosquitoes, and was responsible for 438000 deaths worldwide in 2015 , according to the last World Malaria report. ${ }^{1}$ The resistance of parasites to available and affordable medicines has become a widespread problem in exposed countries, making the search for new antimalarial compounds essential. As the immeasurable therapeutic potential of plants is well-established, ${ }^{2}$ natural products could be an interesting source of new antimalarial drugs. Indeed, according to Newmann and Cragg, more than $60 \%$ of the antiparasitic drugs discovered between 1981 and 2014 were unaltered natural products (12.5\%), natural product derivatives $(31.3 \%)$, or synthetic drugs with a natural product
\end{abstract}

pharmacophore $(18.8 \%) .^{3}$ The endemic plants of the Mascarene Islands appear to be good candidates for study because of their scarcity; most of them are being pharmacologically studied for the first time, increasing the chances for the discovery of new active compounds.

Poupartia borbonica J.F. Gmel is a dioecious endemic plant from the Mascarene Islands and belongs to the genus Poupartia in the Anacardiaceae family, as verified in accordance with the International Plant Names Index. The genus is dedicated to the botanist, physician, and anatomist François Poupart (16611709), who described many new Poupartia species, including $P$. borbonica. $^{4}$ 
This plant, commonly known in Reunion Island as "Bois blanc rouge" ("red white wood"), is used in traditional medicine to induce a contraceptive effect. ${ }^{5}$ In the past, it was also used to treat nephritis and boils. ${ }^{6}$ Indeed, the bark of $P$. borbonica has an allegedly diuretic effect. ${ }^{7}$ As far as can be established, the leaves of $P$. borbonica have not been either phytochemically or pharmacologically studied. Preliminary work (Table 1) demonstrated that several extracts of this plant possess interesting in vitro antiplasmodial activities. This study was designed to determine the compounds responsible for this activity.

\section{RESULTS AND DISCUSSION}

Different extraction solvents of dried and pulverized $P$. borbonica leaves were tested to select the starting point of the bioassay-guided fractionation. The resulting extracts were tested against the P. falciparum 3D7 strain (Table 1).

Table 1. Antiplasmodial Activity of the Extracts of $\boldsymbol{P}$. borbonica Leaves against $P$. falciparum

$\begin{array}{ccc}\text { extraction solvent } & \text { yield }(\% \mathrm{~m} / \mathrm{m}) & \mathrm{IC}_{50}(\mu \mathrm{g} / \mathrm{mL}) n=3 \\ \text { EtOAc } & 1.66 & 2.43 \pm 0.5 \\ n \text {-hexane } & 1.13 & 3.28 \pm 0.2 \\ \mathrm{CH}_{2} \mathrm{Cl}_{2} & 1.05 & 3.25 \pm 0.7 \\ \mathrm{MeOH} & 19.04 & 16.23 \pm 4.3\end{array}$

First, the methanol extract, obtained with a much higher yield, was phytochemically investigated to determine its major compounds. Five known phenolic compounds were isolated: ellagic acid and the four flavonoids, isoquercitrin, quercitrin, $3^{\prime}$ $O$-hydroxysulfonylquercetin, and quercetin, which showed high to low activity against the $P$. falciparum strain. The structures of these known compounds, except 3'-O-hydroxysulfonylquercetin, were elucidated by comparison of their ${ }^{1} \mathrm{H}$ NMR and UV spectra and HPLC retention behaviors against standard compounds.

The major compound of this extract was $3^{\prime}$-O-hydroxysulfonylquercetin, a rare flavonoid inorganic ester. It was isolated by preparative HPLC using a mobile phase containing TFA $(0.05 \%)$. When the solvent of the fraction was removed under vacuum in a rotary evaporator at a temperature $<30{ }^{\circ} \mathrm{C}$, degradation of the $3^{\prime}$-O-hydroxysulfonylquercetin to quercetin was observed based on the HPLC retention time. The acid of the mobile phase was then changed to HOAc (0.1\%) and eventually to formic acid ( $0.1 \%)$. However, this mobile-phase modification did not preclude hydrolysis of the hydroxysulfonyl ester. To avoid this problem, the TFA was removed from the fraction directly by liquid/liquid extraction using $\mathrm{Et}_{2} \mathrm{O}$, and the aqueous fraction was then lyophilized. The instability of these types of compounds is the main reason why they are not often isolated. However, sulfate conjugation of flavonoid compounds has been widely observed in many plant families ${ }^{8}$ to facilitate their storage. ${ }^{9}$ Hydroxysulfonylquercetin compounds have been reported in the Asteraceae genus in the species Oenanthe crocata, Flaveria bidentis, and Flaveria choloraefolia, ${ }^{8,10}$ as well as in Cuphea carthagenensis (Lythraceae). ${ }^{11}$

The structure of 3 '-O-hydroxysulfonylquercetin was established by comparison with spectra recorded for a quercetin standard by mass spectrometry, ${ }^{1} \mathrm{H} \mathrm{NMR}$, and UV data analysis. 3'-O-Hydroxysulfonylquercetin was assigned the formula $\mathrm{C}_{15} \mathrm{H}_{10} \mathrm{O}_{10} \mathrm{~S}$ from the $[\mathrm{M}+\mathrm{H}]^{-}$ion at $\mathrm{m} / \mathrm{z}=$ 381.5998 in the ESI-HR-TOF-MS data (calcd for $\mathrm{C}_{15} \mathrm{H}_{10} \mathrm{O}_{10} \mathrm{~S}$, $381.9995)$. The presence of an ion at $m / z 383.5998(5.05 \%)$ confirmed the presence of a sulfur atom. UV data analysis confirmed the presence of an auxochrome group and a modification of the quercetin B-ring. Similar UV spectra have been described by O'Leary and co-workers. ${ }^{12}$ The position of the hydroxysulfonyl group was deduced from the chemical shift of $\mathrm{H}-2^{\prime}$ compared to a quercetin standard.

Quercetin is a natural flavonoid found in a wide range of plants and is known to have multiple therapeutic properties, such as anticancer, anti-inflammatory, antiobesity, and antimicrobial activities, as reviewed by D'andrea ${ }^{13}$ and by Gupta et al. ${ }^{14}$ Even though data concerning the antiplasmodial activity of quercetin have shown that this flavonol inhibits the growth of different P. falciparum strains, ${ }^{14}$ its clinical application may be limited because of its low solubility in aqueous media. On the other hand, it has been shown that increasing the solubility of quercetin by preparing aminoalkylated analogues improved its antiplasmodial activity. ${ }^{15}$ The presence of a sulfate group on quercetin may act similarly by increasing solubility.

The antiplasmodial activities of both $3^{\prime}$-O-hydroxysulfonylquercetin and quercetin were evaluated on the $P$. falciparum 3D7 strain. The $\mathrm{IC}_{50}$ value of quercetin was assessed in this study at $17.54 \pm 3.9 \mu \mathrm{M}$, in agreement with reported data. ${ }^{16}$ The $3^{\prime}$-O-hydroxysulfonylquercetin was found to be less active, with an $\mathrm{IC}_{50}$ value of $40.58 \pm 8.1 \mu \mathrm{M}$. This decrease in activity, despite the higher solubility compared to quercetin, may be due to the steric bulk of the B-ring. In contrast, an aminoalkylated group added to the A-ring of quercetin increased its antiplasmodial activity. ${ }^{15}$ Isoquercitrin and ellagic acid, whose antiplasmodial activities corresponded to reported data, ${ }^{16,17}$ were also tested. Their $\mathrm{IC}_{50}$ values were calculated to be 42.34 $\pm 5.4 \mu \mathrm{M}$ and $2.6 \pm 0.98 \mu \mathrm{M}$, respectively.

The crude EtOAc extract was found to exhibit the highest activities. Fractionation of the EtOAc extract on an open column led to eight fractions, A to $H$. Evaluation of the antiplasmodial activity of these fractions showed that fractions $\mathrm{E}$ and $\mathrm{G}$ were the most active, with $\mathrm{IC}_{50}$ values of 0.38 and 0.72 $\mu \mathrm{g} / \mathrm{mL}$, respectively.

Purification of fractions E and G using preparative HPLC afforded three compounds 1-3, which were identified using NMR and LC-MS analysis (Chart 1). Their IR spectra showed a broad $\mathrm{OH}$ absorption band at $3383 \mathrm{~cm}^{-1}$ and a strong absorption band of a conjugated carbonyl moiety at $1667 \mathrm{~cm}^{-1}$. The three compounds were not separable by TLC but were separable by reverse-phase HPLC, even though the difference in retention times between 1 and 2 was small.

Compound 1 was assigned the formula $\mathrm{C}_{23} \mathrm{H}_{38} \mathrm{O}_{4}$ from the $[\mathrm{M}+\mathrm{H}]^{+}$ion at $m / z=379.2845$ by HR-ESI-TOF-MS analysis (calcd for $\mathrm{C}_{23} \mathrm{H}_{39} \mathrm{O}_{4}=379.2848$ ). ${ }^{13} \mathrm{C}$ APT NMR and editedHSQC experiments indicated the presence of 1 methyl, 5 methine (including 4 olefinic), 14 methylene, and 3 carbons with no attached protons, including a carbonyl function. Examination of the COSY spectrum showed that most of the methylenes were involved in an alkyl chain bearing one of the two olefinic functionalities and terminated by Me-17'. The other end of this spin system consisted of methylene $\mathrm{H}-\mathbf{1}^{\prime}$, methine $\mathrm{H}-2^{\prime}$, and methylene $\mathrm{H}-3^{\prime}$. Both $\mathrm{H}-1^{\prime}$ and $\mathrm{H}-5$ correlated with the deshielded C-1 and C- 6 resonances. The former had a chemical shift that was characteristic of a hemiketal. Additionally, the deshielded C-2' resonance 


\section{Chart 1}<smiles>O=c1c(O)c(-c2ccc(O)c(OS(=O)(=O)O)c2)oc2c(O)c(O)cc(O)c12</smiles>

3'-O-hydroxysulfonylquercetin
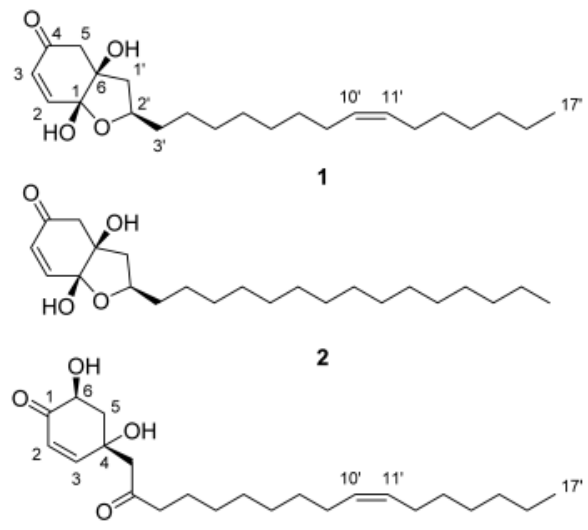

3

suggested that it was bonded to an oxygen. Because only two protons of hydroxy groups were visible in the ${ }^{1} \mathrm{H}$ NMR spectra and neither correlated to $\mathrm{C}-2^{\prime}$ in the HMBC spectrum, it was deduced that $\mathrm{C}-1$ and $\mathrm{C}-2$ ' were linked through an ether bond, with $\mathrm{C}-1$ bearing an additional hydroxy group, in accordance with its chemical shift. The more shielded C-6 was thus connected to both $\mathrm{C}-1^{\prime}$ and $\mathrm{C}-5$ and to a hydroxy group. This was in accordance with the observed HMBC cross-peaks of both hydroxy protons and C-6. The 1-OH proton also correlated with $\mathrm{C}-2$, whose proton was part of an olefinic spin system that included $\mathrm{H}-3$ as per the COSY spectrum. H-2 further exhibited an HMBC cross-peak with C-4, while $\mathrm{H}-3$ correlated with $\mathrm{C}-5$, suggesting a six-membered ring comprising $\mathrm{C}-1$ through C-6. The remaining HMBC cross-peaks were consistent with the proposed bicyclic structure. TOCSY experiments with increasing mixing times indicated that the acyclic olefinic group was closer to the terminal methyl group than the bicyclic functionality. Its position was inferred from the literature, as all known Anacardiaceae cyclohexenones possess $\Delta^{10^{\prime}\left(11^{\prime}\right)}$ double bonds. This position was confirmed by an intense ion at $m / z 145$ observed in the GC-EI-MS spectrum of an $\alpha, \beta$-bis(methylthio)-derivative of compound 1 , obtained by a DMDS derivatization procedure. The $(Z)$ configuration of the $\Delta^{10^{\prime}\left(11^{\prime}\right)}$ olefinic moiety was confirmed by comparison of the chemical shifts of C-9' and C-12' with literature values. ${ }^{8}$ Thus, the structure of compound 1 was defined as $(2 R, 3 \mathrm{a} R, 7 \mathrm{a} R)-2$ - $[(Z)$-pentadec-8-en-1-yl]-3a,7a-dihydroxy2,3,3a,7a-tetrahydrobenzofuran-5(4H)-one, and named Poupartone A.

The NMR spectra of compound 2 indicated that it featured the same fused ring structure as 1 with a saturated aliphatic chain, while its HR-ESI-TOF-MS sodium adduct ion at $\mathrm{m} / z=$ 403.2812 indicated the presence of two more protons for a formula of $\mathrm{C}_{23} \mathrm{H}_{40} \mathrm{O}_{4}$ (calcd for $\left[\mathrm{C}_{23} \mathrm{H}_{40} \mathrm{O}_{4} \mathrm{Na}\right]^{+}$, 403.2824). The broad multiplets of the aliphatic methylene protons integrated for two more protons than in compound 1. Thus, the structure of compound 2 was assigned as $(2 R, 3 \mathrm{a} R, 7 \mathrm{a} R)-2$ pentadecyl-3a,7a-dihydroxy-2,3,3a,7a- tetrahydrobenzofuran$5(4 \mathrm{H})$-one, and named Poupartone B.

Compound 3 has the same molecular formula as 1 , given its HR-ESI-TOF-MS ion at $m / z=379.2843$. However, while the aliphatic chain was the same as in compound 1 , its spectra differed from the two former compounds with respect to the cyclic part of the molecule. A two-proton spin system of the olefinic moiety and a three-proton spin system comprising H-6 and $\mathrm{H}_{z}-5$ were evident in the ${ }^{1} \mathrm{H}$ NMR spectrum. The $\mathrm{H}-6$ resonance was deshielded, indicating C-6 substitution by a hydroxy group. Both $\mathrm{H}-5$ and $\mathrm{H}-3$ showed HMBC cross-peaks with the C-1 carbonyl. Additional HMBC cross peaks, including $\mathrm{H}-2 / \mathrm{C}-4$ and $\mathrm{H}-6 / \mathrm{C}-4$, completed a six-membered ring with the deshielded $\mathrm{C}-4$ carrying the aliphatic chain and an additional hydroxy group. $\mathrm{H}-1^{\prime}$ exhibited HMBC cross-peaks with both C-4 and the C-2' carbonyl carbon. A spin system starting from $\mathrm{H}-3^{\prime}$ constituted the remainder of the aliphatic chain. Thus, compound 3 was found to be a $2^{\prime}$-oxo analogue of 4,6-dihydroxy-4 $\left[\left(10^{\prime} \mathrm{Z}\right)\right.$-heptadecenyl $]$ cyclohexenone, ${ }^{18}$ and its structure was defined as (4S,6R)-4,6-dihydroxy-4-[(Z)-2oxoheptadec-10-en-yl]-cyclohexen-2-enone, and named Poupartone $\mathrm{C}$. The key correlations observed in the HMBC and COSY NMR spectra of compounds 1-3 are shown in Figure 1.
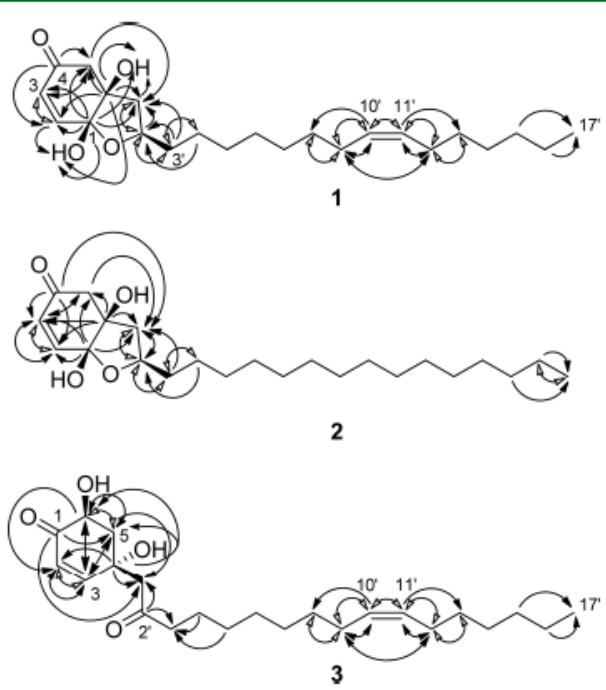

Figure 1. Key correlations observed in the HMBC ( $)$ and COSY (D) NMR spectra of compounds 1-3.

The absolute configurations of compounds 1-3 were established by comparison of their experimental electronic circular dichroism (ECD) and ${ }^{13} \mathrm{C}$ NMR data with those predicted using the DFT/ $\omega \mathrm{B} 97 \mathrm{XD} / 6-31+\mathrm{G}(\mathrm{d}, \mathrm{p})$ method. The modified probability (DP4+) method was used, which differs from the DP4 method by the inclusion of unscaled data and the use of higher levels of theory for the NMR calculation procedure. ${ }^{9}$ On the basis of geometrical considerations, four possible isomers were conceivable: $1 S, 6 R, 2^{\prime} R / 1 R, 6 S, 2^{\prime} S$, $1 S, 6 R, 2^{\prime} S / 1 R, 6 S, 2^{\prime} R, 1 S, 6 S, 2^{\prime} R / 1 R, 6 R, 2^{\prime} S$, and $1 S, 6 S, 2^{\prime} S /$ $1 R, 6 R, 2 R$ (Figure 2).

The comparison of experimental and calculated NMR spectra allowed the determination of the relative configuration of 1 and 2 as $\left(1 S, 6 S, 2^{\prime} S / 1 R, 6 R, 2^{\prime} R\right)$ with a DP4+ probability of $100 \%$. The $\left(1 R, 6 R, 2^{\prime} R\right)$ absolute configuration was then assigned by comparing the experimental and calculated ECD 


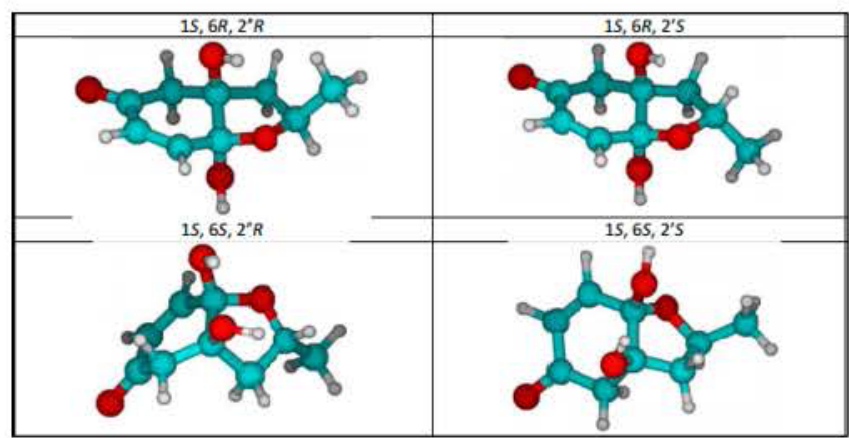

Figure 2. Diagram of the most stable configurations of the four isomers of compound 1 .

spectra at the TDA/RI-B2GP-PLYP/def2-TZVPP/SMD level in $\mathrm{MeOH}$ (Supporting Information).

The comparison of the experimental and calculated NMR spectra of compound 3 allowed the definition of the relative configuration as $(4 R, 6 \mathrm{~S} / 4 S, 6 R)$ with a $\mathrm{DP} 4+$ probability of $100 \%$. The $(4 S, 6 R)$ absolute configuration was then assigned by comparing the experimental and calculated ECD spectra at the TDA/RI-B2GP-PLYP/def2-TZVPP/SMD level in $\mathrm{MeOH}$.

The compounds from the EtOAc extract were tested in vitro on the parasitic protozoa P. falciparum, and all showed high levels of activity against both chloroquine-sensitive strain W2 and chloroquine-resistant strain 3D7 (Table 3) with $\mathrm{IC}_{50}<2$ $\mathrm{mM}$.

This class of compounds was previously observed in the Anacardiaceae family in Tapirira guianensis and showed antiprotozoal and antibacterial activities. ${ }^{21}$ One of the compounds, described by Roumy et al. as 1,2',4,5-tetrahydroxy-1-[10'Z-heptadecenyl]-2-cyclohexene, had a much lower activity level $(86.4 \pm 2.6 \mu \mathrm{g} / \mathrm{mL}$ on $P$. falciparum $) .^{21}$ Thus, it seems there is a positive effect on activity by the presence of a C-1 carbonyl and of an oxidation on C-2' for compound 3. Similar observations can also be established for compounds 12 possessing $\Delta^{2(3)}$ double bonds, as the compound devoid of this double bond, 1,3,4,6-tetrahydroxy-1,2'-epoxy-6-[10'Zheptadecenyl]cyclohexane, is less active, with an $\mathrm{IC}_{50}$ on Plasmodium falciparum F32 strain of $101.3 \pm 3.8 \mu \mathrm{M} .^{21}$ Other cyclohexenone derivatives were also described in Tapirira obtusa, ${ }^{22}$ as well as in Pistacia vera. ${ }^{23}$

The cytotoxic activities of these types of compound were highlighted in Tapirira guianensis. ${ }^{18}$

A Chinese patent (CN 1733748 A, Feb 15, 2006) was filed for a compound that has a structure similar to that of compound 1 but with a longer side chain and a different configuration of the bicyclic system. It was obtained from extracts of Choerospondias axillaris, a plant from the Anacardiaceae, and possesses cell cycle inhibitory and apoptosis inductor effects allowing its use as an antitumor and anticancer agent. ${ }^{24}$ This finding was a factor in the decision to analyze the cytotoxicity of $1-3$.

These results show that compounds 1-3 are the bioactive compounds responsible for the activity of the EtOAc extract of the leaves of $P$, borbonica but also for the cytotoxicity which is similar to related compounds. ${ }^{21}$ Compound 1 has the most promising activity but is also the most cytotoxic, with an SI of 1.76 on the P. falciparum 3D7 strain and WI38 cells. However, the antiplasmodial activity was not due to hemolysis, because neither the extract nor the isolated compounds induced red blood cell lysis at the highest concentration tested.
Using the method described by Deharo and Ginsburg, ${ }^{20}$ the cyclohexenones 1-3 explain almost $50 \%$ of the activity of the EtOAc crude extract against $P$. falciparum (compound 1: 21.5\%; compound 2: $21.4 \%$; compound 3: $2.9 \%$ ). As compound 1 was the most abundant, an in vivo antimalarial assay was performed using P. berghei-infected mice. Compound 1 showed an inhibition of 59.1 and $69.5 \%$ of parasitic growth at days 5 and 7 postinfection, respectively (Figure 3 ). Compound 1 significantly reduced parasitemia compared to the negative control. However, it was not devoid of toxicity, and despite the reduction of parasitemia, mice started to die on day 7 .

Zebrafish larvae were used as a model to observe the toxicity of compound 1. The embryonic development of zebrafish is rapid, and the optical transparency of the embryos is convenient for investigating the causes of lethality. ${ }^{25}$ It is also possible to observe developmental effects of a drug. Even if zebrafish cannot replace rodent models, they are useful for rapidly determining the toxicity of a drug in the early stages of an investigation. Embryos were dechorionated because the chorion has a protective function and isolates the embryo physically and chemically from external environmental conditions. $^{26}$ In the first step of analysis, logarithmic concentration series were used for range-finding. During the period of $24 \mathrm{~h}$ postfertilization (hpf) to $72 \mathrm{hpf}$, it was observed that all embryos died within 1 day after introduction of $10 \mu \mathrm{g} /$ $\mathrm{mL}$ of compound 1 . The second part of the test enabled more detailed observations of toxicity at a range of specific drug levels. After the first treatment doses, all embryos died at doses of 10,5 , or $3 \mu \mathrm{g} / \mathrm{mL}$. At these concentrations, the embryos disintegrated, suggesting high contact toxicity. Neither 2.5 nor $2 \mu \mathrm{g} / \mathrm{mL}$ doses induced disintegration, but a few (5\%) of the embryos developed bradycardia. No toxicity was observed at 1 $\mu \mathrm{g} / \mathrm{mL}$. Cumulative mortality was observed at 48 and $72 \mathrm{hpf}$, after two and three treatment doses, respectively. The $2.5 \mu \mathrm{g} /$ $\mathrm{mL}$ concentration dose was lethal for all embryos at $48 \mathrm{hpf}$. At $2 \mu \mathrm{g} / \mathrm{mL}, 60 \%$ of the embryos died at $48 \mathrm{hpf}$, while the survivors developed a large decrease in pericardial function and body axis deformation and died at $72 \mathrm{hpf}$ after the third dose. In contrast, at $72 \mathrm{hpf}$, no significant mortality or morphological modifications were observed in embryos treated with $1 \mu \mathrm{g} / \mathrm{mL}$.

The toxicity results from using a zebrafish embryo model may be an indication of the toxicity observed in mice. Indeed, although their cardiac morphology is simpler than the mammalian one, many features of the zebrafish heart are similar to those of mice. ${ }^{27}$

In conclusion, the bioguided fractionation of an extract of the leaves of $P$. borbonica led to the isolation of three new alkyl cyclohexenone derivatives (1-3) that could explain, at least in part, the antiplasmodial activity of the EtOAc crude extract. These compounds showed high in vitro antiplasmodial activities, without any hemolysis, on the chloroquine-sensitive $P$. falciparum strain as well as on the resistant strain and displayed some toxicity. The in vivo assays performed on mice confirmed the high antimalarial activity of compound 1 , even if toxicity was recorded from day 7 . Regarding the toxicity test on the zebrafish embryo model, compound 1 seems to be responsible for heart failure. The mechanisms of action of these high potential antiplasmodial cyclohexenones, as well as elucidation of their structure-activity relationships, still need to be investigated. Ellagic acid, which is known to have high antiplasmodial activity, ${ }^{17,29}$ seems to be the compound that explains the major part of the activity of the methanol crude extract, even if other compounds may act in synergy or have an 


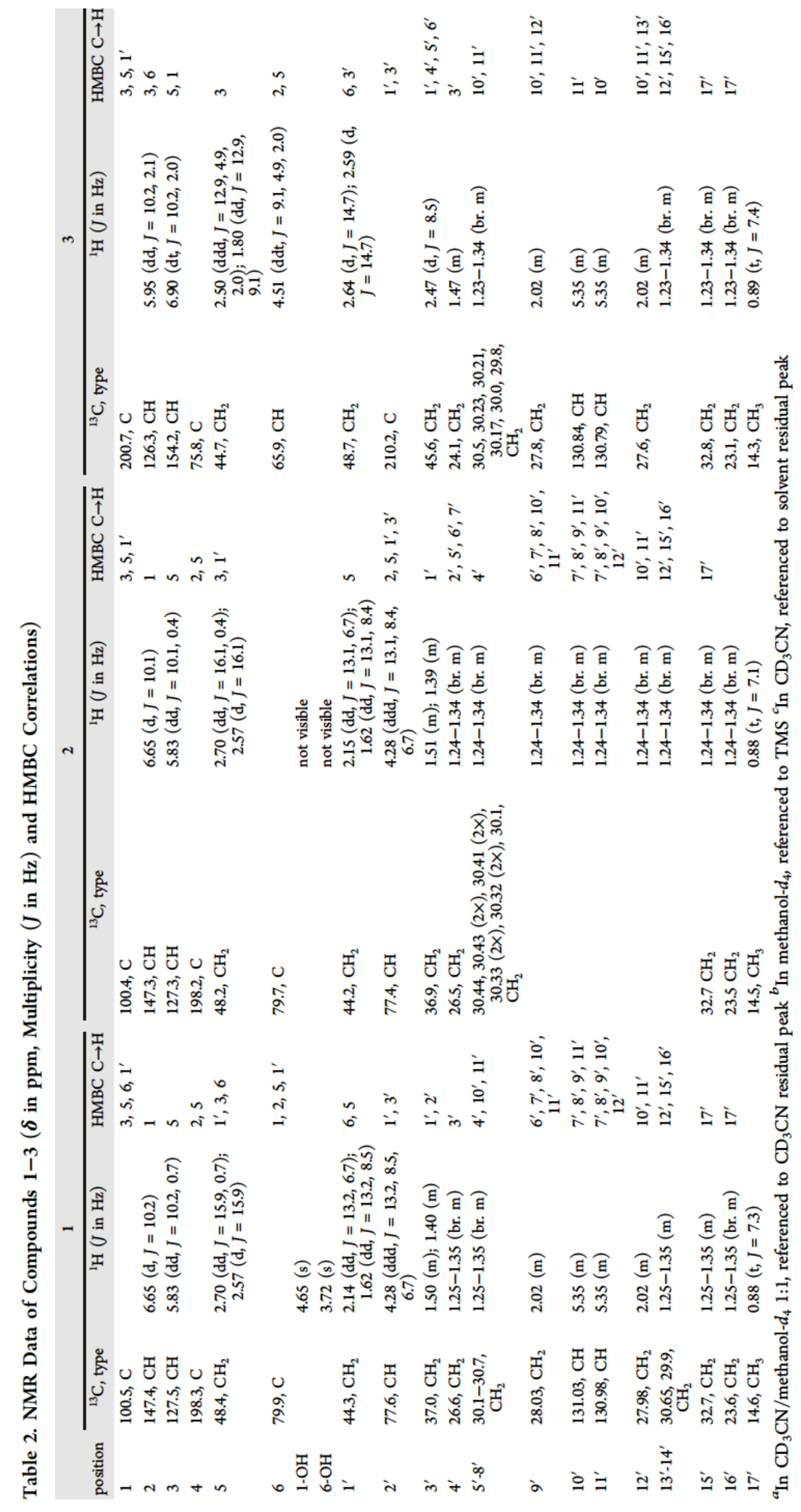


Table 3. Antiplasmodial and Cytotoxic Activities of Compounds 1-3 and the EtOAc Extract

\begin{tabular}{|c|c|c|c|c|c|c|c|}
\hline \multirow[b]{2}{*}{ samples } & \multicolumn{2}{|c|}{$\begin{array}{l}\text { P. falciparum } \mathrm{IC}_{50}(\mu \mathrm{g} / \mathrm{mL}) \\
\operatorname{IC}_{50}(\mu \mathrm{M})(n=3)\end{array}$} & \multicolumn{2}{|c|}{$\begin{array}{c}\text { cytotoxicity } \mathrm{IC}_{50}(\mu \mathrm{g} / \mathrm{mL}) \\
\mathrm{IC}_{50}(\mu \mathrm{M})(n=2)\end{array}$} & \multicolumn{2}{|c|}{$\begin{array}{l}\text { selectivity index } \\
\text { (SI) }\end{array}$} & \multirow[b]{2}{*}{ hemolysis (\%) } \\
\hline & W2 & 3D7 & $\mathrm{HeLa}$ & WI38 & WI38/W2 & WI38/3D7 & \\
\hline \multirow[t]{2}{*}{1} & $0.21 \pm 0.010$ & $0.34 \pm 0.040$ & $0.80 \pm 0.120$ & $0.60 \pm 0.380$ & 2.86 & 1.76 & $<1 \%$ \\
\hline & $0.55 \pm 0.003$ & $0.90 \pm 0.015$ & $2.10 \pm 0.316$ & $1.58 \pm 1.000$ & & & \\
\hline \multirow[t]{2}{*}{2} & $0.37 \pm 0.050$ & $0.69 \pm 0.200$ & $1.44 \pm 0.340$ & $1.04 \pm 0.500$ & 2.81 & 1.51 & $<1 \%$ \\
\hline & $0.97 \pm 0.130$ & $1.81 \pm 0.520$ & $3.77 \pm 0.890$ & $2.73 \pm 1.300$ & & & \\
\hline \multirow[t]{2}{*}{3} & $0.48 \pm 0.040$ & $0.43 \pm 0.160$ & $1.31 \pm 0.430$ & $1.01 \pm 0.820$ & 2.10 & 2.34 & $<1 \%$ \\
\hline & $1.27 \pm 0.105$ & $1.13 \pm 0.420$ & $3.45 \pm 1.130$ & $2.66 \pm 2.160$ & & & \\
\hline EtOAc extract & $1.78 \pm 0.390$ & $2.43 \pm 0.500$ & $3.37 \pm 0.350$ & $3.23 \pm 0.350$ & 1.81 & 1.33 & $<1 \%$ \\
\hline \multirow[t]{2}{*}{ artemisinin } & $0.010 \pm 0.002$ & $0.004 \pm 0.001$ & NT & NT & & & NT \\
\hline & $0.035 \pm 0.007$ & $0.014 \pm 0.004$ & & & & & \\
\hline \multirow[t]{2}{*}{ camptothecin } & NT & NT & $0.080 \pm 0.015$ & $0.030 \pm 0.011$ & & & NT \\
\hline & & & $0.230 \pm 0.043$ & $0.086 \pm 0.032$ & & & \\
\hline
\end{tabular}

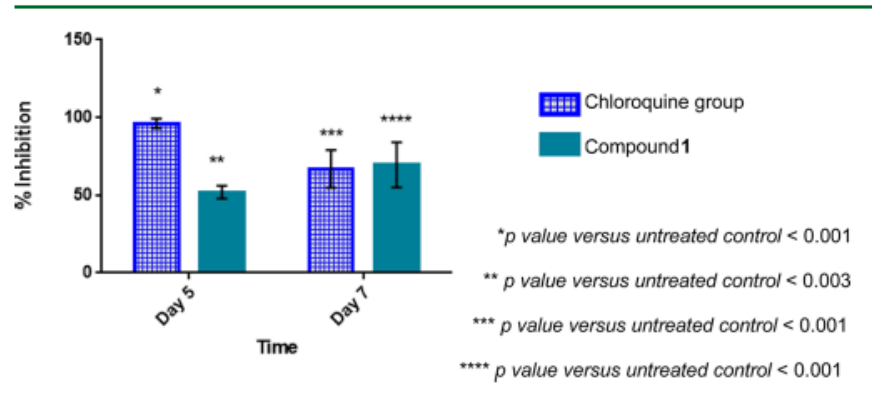

Figure 3. In vivo parasitemia inhibition in mice infected by Plasmodium berghei and treated intraperitoneally with $15 \mathrm{mg} / \mathrm{kg} / \mathrm{d}$ of compound 1.

additive action. The moderate antiplasmodial activity of $3^{\prime}-O$ hydroxysulfonylquercetin is described here for the first time, as is the suggestion that the B-ring of quercetin plays an important role in that activity.

\section{EXPERIMENTAL SECTION}

General Experimental Procedures. The UV spectra were recorded in $\mathrm{MeOH}$ on a Hitachi U-2910 spectrophotometer. The ECD spectra were recorded in $\mathrm{MeOH}$ at $25{ }^{\circ} \mathrm{C}$ using a Jasco J-810 spectrophotometer. The FT-IR spectra were measured on a Frontier PerkinElmer spectrophotometer equipped with an ATR module. ${ }^{1} \mathrm{H}$ and ${ }^{13} \mathrm{C}$ NMR spectra were recorded in $\mathrm{CD}_{3} \mathrm{CN}$ and/or $\mathrm{MeOH}-d_{4}$ on a Bruker AVANCE I $500 \mathrm{MHz}$ spectrometer equipped with a cryoprobe. 2D experiments were performed using standard Bruker microprograms. LC/MS was performed on a Thermo Scientific LTQ orbitrap XL mass spectrometer with ESI source in positive mode with an RP select B LiChrospher $60(250 \mathrm{~mm} \times 4.6 \mathrm{~mm}, 5 \mu \mathrm{m})$ column. All solvents used were analytical grade (Merck, Hohenbrunn, Germany). A Varian ProStar chromatography system with diode array detector was employed to profile the extracts. A Varian ProStar chromatography equipped with a Büchi fraction collector C-660 unit was used to accomplish the preparative isolation. The following columns were employed: Hypersil $\mathrm{C}_{18}(250 \mathrm{~mm} \times 4.6 \mathrm{~mm}, 5 \mu \mathrm{m})$, PFP Luna $(250 \mathrm{~mm} \times 4.6 \mathrm{~mm}, 10 \mu \mathrm{m})$, RP select B LiChrospher 60 $(250 \mathrm{~mm} \times 4.6 \mathrm{~mm}, 5 \mu \mathrm{m})$. GC-MS analysis of compounds 1 and 3 was performed with a Jeol JMS-T100GCV (EI-TOFMS, positive ion mode) apparatus fitted with an Rtx-5 capillary column (Restek $-5 \%$ diphenyl/95\% dimethyl polysiloxane), using the same conditions described by Mansour et al. ${ }^{28}$

Analytical TLC was performed on precoated Si gel $60 \mathrm{~F}_{254}$ (Merck, Hohenbrunn, Germany) plates. After development ( $n$-hexane/EtOAc/ HOAc, 14:6:0.3), the dried plates were observed under $254 \mathrm{~nm}$ and sprayed with sulfuric vanillin and heated for $15 \mathrm{~min}$ at $110{ }^{\circ} \mathrm{C}$ to analyze the EtOAc extract and isolated compounds. TLC plates for the $\mathrm{MeOH}$ extract were developed with EtOAc/formic acid/HOAc/ $\mathrm{H}_{2} \mathrm{O}$
(100:11:11:26) and sprayed with NP-PEG [Natural Product Reagent ( $1 \%$ diphenylboryloxyethylamine in $\mathrm{MeOH}$ ) and polyethylene glycol 4000 (5\% polyethylene glycol 4000 in EtOH)]. The dried plates were examined under ultraviolet light $(366 \mathrm{~nm})$.

Plant Material. The male plants were collected on Reunion Island and identified by $\mathrm{H}$. Thomas (Parc National de La Réunion). Voucher specimens (no. RUN 028F, TCN-P022F) were deposited in the Herbarium of the University of Reunion Island. The leaves were airdried at room temperature with no direct sunlight and then pulverized using an electrical grinder. Extracts were prepared with $5 \mathrm{~g}$ of powdered dried material and then macerated three times in $50 \mathrm{~mL}$ of solvent $\left(\mathrm{MeOH}, \mathrm{EtOAc} n\right.$-hexane, or $\left.\mathrm{CH}_{2} \mathrm{Cl}_{2}\right)$ for $30 \mathrm{~min}$ with constant shaking at room temperature. The filtrates were pooled and evaporated to dryness under reduced pressure at $40^{\circ} \mathrm{C}$.

The leaves of $P$. borbonica were air-dried $(200 \mathrm{~g})$, pulverized, and extracted by maceration with EtOAc $(2 \mathrm{~L}, 30 \mathrm{~min} \times 3)$ at room temperature. After filtration, the solvent was evaporated at low temperature $\left(<40^{\circ} \mathrm{C}\right)$ under pressure. The resulting dried extract $(1.0$ g) was defatted using a two-phase solvent system, $n$-hexane $/ \mathrm{MeOH} /$ $\mathrm{CH}_{3} \mathrm{CN}$ (6:0.5:3.5), as described by Roumy et al. ${ }^{21}$ The biologically active lower phase was dispersed in EtOAc and subjected to open silica column chromatography, eluting with a gradient of EtOAc and $\mathrm{CH}_{2} \mathrm{Cl}_{2}$ from 5:95 to 100:0. A total of 67 fractions were collected and analyzed by analytical TLC and grouped into 8 subfractions (A-H) on the basis of the TLC profiles. The biologically active fractions E and G $(53 \mathrm{mg})$ were grouped on the basis of their HPLC profiles and subjected to a preparative HPLC column $(30 \mathrm{~cm} \times 2.5 \mathrm{~cm})$ using a LichroPrep RP-18 (25-40 $\mu \mathrm{m}$, Merck) support. The flow rate was 30 $\mathrm{mL} / \mathrm{min}$ with a binary solvent system of formic acid $0.1 \%$ in $\mathrm{H}_{2} \mathrm{O}$ and $\mathrm{MeOH}$ (40:60 to 0:100 v/v in $30 \mathrm{~min}$ ). Compounds 1-3 were eluted between the 15th and 25th minute. Further purification of compound 3 was performed by preparative TLC eluted with $n$-hexane/EtOAc/ HOAc (14:6:0.3).

Isolation of the Phenolic Compounds in the MeOH Extract of $P$. borbonica Leaves. Leaves of P. borbonica were air-dried (100 $\mathrm{g})$, pulverized, and extracted by maceration with $\mathrm{MeOH}$ (1L, 30 min $\times 3)$ at room temperature. After filtration, the solvent was evaporated at a temperature below $40^{\circ} \mathrm{C}$ under pressure. The resulting dried $(18$ g) extract was fractionated by preparative HPLC with a LichroPrep RP-18 (25-40 $\mu$ m, Merck, Hohenbrunn, Germany) support column using a gradient of trifluoroacetic acid $(0.05 \%)$ and $\mathrm{CH}_{3} \mathrm{CN}$ (100:0 to $60: 40 \mathrm{v} / \mathrm{v}$ ). Fractions containing 3 '-O-hydroxysulfonylquercetin were washed 6 times with $30 \mathrm{~mL}$ of $\mathrm{Et}_{2} \mathrm{O}$ to remove trifluoroacetic acid. The same procedure was performed without TFA to obtain ellagic acid.

In Vitro Antiplasmodial Activity. Continuous in vitro cultures of asexual erythrocyte stages of $P$. falciparum, chloroquine-sensitive strain 3D7 (originally isolated from a patient living near Schipol airport in The Netherlands), and chloroquine-resistant strain W2 (originally isolated from a Lao refugee in 1980 $)^{30,31}$ were maintained following the procedure of Trager and Jensen. ${ }^{32}$ The host cells were human red blood cells (A+). The culture medium comprised RPMI 1640 (Gibco, 
Fisher Scientific, Loughborough, U.K) containing $\mathrm{NaHCO}_{3}(32 \mathrm{mM})$, HEPES ( $25 \mathrm{mM})$, and L-glutamine. The medium was supplemented with $1.76 \mathrm{~g} / \mathrm{L}$ of glucose (Sigma-Aldrich, Machelen, Belgium), $44 \mathrm{mg} /$ $\mathrm{mL}$ of hypoxanthin (Sigma-Aldrich, Machelen, Belgium), $100 \mathrm{mg} / \mathrm{L}$ of gentamycin (Gibco, Fisher Scientific, Loughborough, U.K.), and 10\% human pooled serum (A+), as described by Bero et al. ${ }^{33}$ Strains were obtained from the Malaria Research and Reference Reagent Resource Center, MR4.

Solutions of crude extracts were prepared in DMSO at $10 \mathrm{mg} / \mathrm{mL}$. The highest concentration of solvent to which the parasites were exposed was $1 \%$. At this concentration, the extract did not show any toxicity to $P$. falciparum. The solutions of tested extracts and compounds were diluted in medium; each test sample was applied in a series of eight 2 -fold dilutions in a 96-well plate and tested in triplicate. The parasitemia was $2 \%$, and the hematocrit was $1 \%$, as described by Murebwayire et al. ${ }^{34}$ Parasite growth was estimated after $48 \mathrm{~h}$ incubation by the determination of lactate dehydrogenase $(\mathrm{pLDH})$ activity, according to the methods described by Makler et al. $^{35}$ Artemisinin (Sigma-Aldrich, Machelen, Belgium) at an initial concentration of $100 \mathrm{ng} / \mathrm{mL}$ was used as positive control in all experiments. $\mathrm{IC}_{50}$ values were calculated from graphs.

In Vitro Cytotoxic Activity. Assays were performed on HeLa cells to evaluate the cytotoxicity potential of crude extracts and isolated compounds. Compounds were tested in 96-well microplates using the tetrazolium salt WST-1 (Roche Diagnostics Belgium, Vilvoorde, Belgium) colorimetric assay based on the cleavage of the reagent by mitochondrial succinate-tetrazolium reductase in living cells. Cells (6000) were seeded per well in $200 \mu \mathrm{L}$ of medium supplemented with adequate concentrations of the tested drugs. After $48 \mathrm{~h}$ of incubation, $10 \mu \mathrm{L}$ of WST-1 was added to each well. After $30 \mathrm{~min}$ at $37^{\circ} \mathrm{C}$, the plates were shaken, and absorbance values were recorded at $450 \mathrm{~nm}$. The absorbance values were expressed in percentage terms compared to untreated control cells. $\mathrm{IC}_{50}$ values were calculated from graphs. The HeLa cells were obtained from the Laboratory of Medical Chemistry, GIGA, ULg.

Selectivity Index. The selectivity index was calculated as the ratio between the cytotoxic activity on WI38 cells $\left(\mathrm{IC}_{50}\right)$ and $3 \mathrm{D} 7$ or W2 antiparasitic activities $\left(\mathrm{IC}_{50}\right)$.

In Vitro Hemolytic Activity. Hemolysis assays were performed according to a reported procedure ${ }^{37}$ with EtOAc crude extract and isolated compounds. A red blood cell suspension (A+, 10\% in PBS (v/ v)) was incubated with extract or isolated compounds in triplicate. The final concentrations were $100 \mu \mathrm{g} / \mathrm{mL}$ for the extract and $10 \mu \mathrm{g} / \mathrm{mL}$ for each isolated compound (DMSO < 1\%). After agitation at room temperature for $1 \mathrm{~h}$, the mixtures were centrifuged for $5 \mathrm{~min}$ at 2000 $\mathrm{rpm}$, and $150 \mu \mathrm{L}$ of each supernatant was transferred to a 96-microwell plate to measure the absorbance (OD) at $550 \mathrm{~nm}$ with a microplate reader. The positive control was Triton X-100 1\% (v/v) (corresponding to $100 \%$ red blood cell lysis) and PBS as the negative control (corresponding to $0 \%$ red blood cell lysis). The percentage of red blood cell lysis $(H)$ was calculated as follows: $H=($ OD550 $\mathrm{nm}$ sample - OD550 nm PBS)/ (OD550 nm Triton X-100 1\% (v/v) - OD550 nm PBS).

Cytotoxic Activity on the Zebrafish Larva. Adult zebrafish (Danio rerio) were maintained while fulfilling the criteria of the Ethical Committee for the Use of Laboratory Animals at the University of Liège. They were maintained at $28{ }^{\circ} \mathrm{C}$ on a $14 \mathrm{~h}$ day/10 h night period, and fertilized eggs were collected, washed with sterile water, and placed in Petri dishes. Larvae were collected, and chorions were removed. Tests were performed in two steps; the first one to determine the range of concentrations to be used to determine $\mathrm{LC}_{50}$ during the second step, by a narrower geometric series, as described by Shaukat et al. ${ }^{36}$ Geometric series were performed in duplicate. First, logarithmic concentrations were tested (10 to $0.001 \mu \mathrm{g} / \mathrm{mL})$. Second, the range of tested concentrations was narrowed and included only between 10 and $1 \mu \mathrm{g} / \mathrm{mL}$. Compound 1 was in DMSO solution and was diluted with the medium used for zebrafish. The DMSO final higher concentration was $0.4 \%$. Twenty-five embryos were used per condition in a 6-well plate. Each well contained $5 \mathrm{~mL}$ of the treatment dose, which was replaced once daily for 3 days. The embryos were observed each day until $72 \mathrm{hfp}$. Twenty-five embryos were used as control, and 25 others were used to control the solvent (DMSO, $0.4 \%)$.

Antiplasmodial Activity Testing in Vivo. The present study was approved by the Ethical Committee for the Use of Laboratory Animals at the University of Liège (no. 721) and was designed according to internationally recognized guidelines.

Female Swiss mice ( 10 weeks old, $25 \pm 2 \mathrm{~g}$ ), obtained from Charles River Laboratories (L'Arbresle, France), were infested by the murine parasite Plasmodium berghei NK173, following the protocol described by Frédérich et al. ${ }^{38}$ Groups of five mice were formed randomly. Parasitized red blood cells $\left(2 \times 10^{7}\right)$ were injected into each mouse by ip injection.

Compound 1 was tested using a protocol based on the 4-day suppressive test of Peters, ${ }^{39}$ as recommended by the WHO. ${ }^{40}$ The treatment dose $(15 \mathrm{mg} / \mathrm{kg}$ ip, dissolved in $7 \%$ Tween 80 and $3 \%$ $\mathrm{EtOH}$ in sterile water) was given $4 \mathrm{~h}$ after infection (day 0 ) and was repeated once daily for the next 3 days. The parasitemia was evaluated by microscope using thin blood smears made from mouse-tail blood and stained with Giemsa (Sigma-Aldrich, Machelen, Belgium) and determined by counting at least 500 erythrocytes. The vehicle solution was used as a negative control (7\% Tween 80 and $3 \% \mathrm{EtOH}$ in sterile water), and chloroquine was used as the positive control, at $4 \mathrm{mg} / \mathrm{kg}$ ip with the same vehicle. The percentage of inhibition of parasite growth was calculated by comparison of the parasitemia counted for the test group with the parasitemia of the negative control group at days 5 and 7.

Computational Methods. The quantum chemical calculations were performed using density functional theory (DFT). The molecular geometries were optimized by the DFT/ $\omega \mathrm{B} 97 \mathrm{XD} / 6-31+\mathrm{G}(\mathrm{d}, \mathrm{p})$ method. Chemical shifts were calculated for the obtained geometries by DFT/TPSSH/6-311+G (2d,p) and reoptimized taking into account the solvent by TDA/RI-B2GP-PLYP/def2-TZVPP/SMD. ECD spectra were calculated from the spectra of individual conformers according to their contribution calculated by Boltzmann weighting.

Poupartone A (1). Colorless oil; UV (MeOH) $\lambda_{\max }(\log \varepsilon) 207$ (2.27); IR 3383 (br OH), 3000 (alkene) 2916, 2833, 1667 (C=O), 1450 (alkane) $\mathrm{cm}^{-1} ;{ }^{1} \mathrm{H},{ }^{13} \mathrm{C}$ NMR (500 MHz, $\mathrm{CDCN}_{3}$ and methanol$\left.d_{4}\right)$ see Table 2; HR-ESI-MS $m / z:=379.2845\left[\mathrm{M}+\mathrm{H}^{+}\right](\mathrm{calcd}$ $\left.\mathrm{C}_{23} \mathrm{H}_{39} \mathrm{O}_{4}, 379.2848\right)$.

Poupartone B (2). Colorless oil; UV (MeOH) $\lambda_{\max }(\log \varepsilon) 210$ (2.18); IR 3383 (br OH), 3000 (alkene) 2917, 2850, 1667 (C=O), 1467 (alkane) $\mathrm{cm}^{-1} ;{ }^{1} \mathrm{H},{ }^{13} \mathrm{C}$ NMR (500 $\mathrm{MHz}, \mathrm{CDCN}_{3}$ ) see Table 2; HR-ESI-MS $m / z:=381.299[\mathrm{M}+\mathrm{H}]^{+}\left(\right.$calcd $\left._{23} \mathrm{H}_{40} \mathrm{O}_{4}, 381.299\right)$ and $403.2812[\mathrm{M}+\mathrm{Na}]^{+}$(calcd for $\left.\mathrm{C}_{23} \mathrm{H}_{40} \mathrm{O}_{4} \mathrm{Na}, 403.2824\right)$.

Poupartone C (3). Colorless oil; UV $(\mathrm{MeOH}) \lambda_{\max }(\log \varepsilon) 200$ (1.90); IR 3400 (br OH), 3000 (alkene) 2915, 2835, 1683, 1667 (C= O), 1450 (alkane) $\mathrm{cm}^{-1} ;{ }^{1} \mathrm{H},{ }^{13} \mathrm{C}$ NMR $\left(500 \mathrm{MHz}, \mathrm{CDCN}_{3}\right.$ and methanol- $\left.d_{4}\right)$ see Table 2; HR-ESI-MS $m / z:=379.2843[\mathrm{M}+\mathrm{H}]^{+}$ (calcd $\mathrm{C}_{23} \mathrm{H}_{39} \mathrm{O}_{4}, 379.2848$ ).

\section{ASSOCIATED CONTENT}

S Supporting Information

The Supporting Information is available free of charge on the ACS Publications website at DOI: 10.1021/acs.jnatprod.6b01019.

1D and 2D NMR spectra of compounds 1-3; experimental and calculated ECD spectra of compound 1 ; dose dependence of cytotoxic activity of 1 on zebrafish larva (PDF)

\section{AUTHOR INFORMATION}

Corresponding Author

*E-mail: Allison.ledoux@ulg.ac.be. Tel: +32-4366-4336.

ORCID

Allison Ledoux: 0000-0002-4052-6336 


\section{Notes}

The authors declare no competing financial interest.

\section{ACKNOWLEDGMENTS}

The authors wish to thank N. Bulté, D. Étienne, I. Ielciu, S. Lhoest, and J.C. van Heugen for their technical assistance and M.F. Herent for recording MS data in the Massmet platform (the equipment was obtained by funding from to the Belgian National Fund for Scientific Research (FNRS) (FRFC 2.4555 .08 and 1.5128.11). E. Boyer, T. Hermann, and M. Felicite are acknowledged for the plant collection. The following reagents were obtained through BEI Resources Repository, NIAID, NIH: Plasmodium falciparum, strain 3D7, MRA-102, contributed by Daniel J. Carucci and strain W2, MRA-157, contributed by Dennis E. Kyle. This research was also supported by the European Commission and the Regional Council of Reunion Island: BIOMOL-TCN program (Activités Thérapeutiques, Cosmétologiques et Nutraceutiques de Molécules Issues de la Biodiversité Terrestre, Marine et Microbienne de la Zone Sud-Ouest de l'Océan Indien), ERDF (European Regional Development Fund) and the Belgian National Fund for Scientific Research (FNRS) (Grant No. T.0190.13).

\section{REFERENCES}

(1) World Health Organization (WHO). World Malaria Report; WHO: Geneva, Switzerland, 2015; p 280.

(2) Bero, J.; Frédérich, M.; Quetin-Leclercq, J. J. Pharm. Pharmacol. 2009, 61, 1401-1433.

(3) Newman, D. J.; Cragg, G. M. J. Nat. Prod. 2016, 79, 629-61.

(4) Maxime BURST, C. L. Poupartia borbonica: Plan national d'actions 2012-2016: outils d'aide à la conservation des espèces végétales menacées d'extinction; Conservatoire Botanique National de Mascarin: Saint-Leu, Réunion, 2011; p 106.

(5) Cordemoy, E. J. d. Flore de l'ile de la Réunion (Phanérogames, Cryptogames vasculaires, Muscinées): avec indication des propriétes économiques et industrielles des plantes; P. Klinsksieck: Paris, 1895; p 614.

(6) Lavergne, R. Le Grand Livre des Tisaneurs et Plantes Médicinales Indigènes de l'Ile de la Réunion; Orphie: Saint-Denis, 1996; Vol. 1.

(7) Adsersen, A.; Adsersen, H. J. Ethnopharmacol. 1997, 58, 189206.

(8) Barron, D.; Varin, L.; Ibrahim, R. K.; Harborne, J. B.; Williams, C. A. Phytochemistry 1988, 27, 2375-2395.

(9) Varin, L.; Ibrahim, R. K. Plant Physiol. 1991, 95, 1254-8.

(10) Barron, D.; Ibrahim, R. K. Phytochemistry 1988, 27, 2362-2363.

(11) Krepsky, P. B.; Farias, M. R.; Côrtes, S. F.; Braga, F. C. Biochem. Syst. Ecol. 2010, 38, 125-127.

(12) O'Leary, K. A.; Day, A. J.; Needs, P. W.; Mellon, F. A.; O'Brien, N. M.; Williamson, G. Biochem. Pharmacol. 2003, 65, 479-491.

(13) D'Andrea, G. Fitoterapia 2015, 106, 256-71.

(14) Gupta, A.; Birhman, K.; Raheja, L; Sharma, S. K.; Kar, H. K. Asian Pac. J. Trop. Dis. 2016, 6, 248-252.

(15) Helgren, T. R; Sciotti, R. J.; Lee, P.; Duffy, S.; Avery, V. M.; Igbinoba, O.; Akoto, M.; Hagen, T. J. Bioorg. Med. Chem. Lett. 2015, $25,327-332$.

(16) Murakami, N.; Mostaqul, H. M.; Tamura, S.; Itagaki, S.; Horii, T.; Kobayashi, M. Bioorg. Med. Chem. Lett. 2001, 11, 2445-7.

(17) Verotta, L.; Dell'Agli, M.; Giolito, A.; Guerrini, M.; Cabalion, P.; Bosisio, E. J. Nat. Prod. 2001, 64, 603-7.

(18) David, J. M.; Chavez, J. P.; Chai, H. B.; Pezzuto, J. M.; Cordell, G. A. J. Nat. Prod. 1998, 61, 287-9.

(19) Grimblat, N.; Zanardi, M. M.; Sarotti, A. M. J. Org. Chem. 2015, $80,12526-34$.

(20) Ginsburg, H.; Deharo, E. Malar. J. 2011, 10 (Suppl1), S1.
(21) Roumy, V.; Fabre, N.; Portet, B.; Bourdy, G.; Acebey, L.; Vigor, C.; Valentin, A.; Moulis, C. Phytochemistry 2009, 70, 305-11.

(22) Correia, S. D.; David, J. M.; David, J. P.; Chai, H. B.; Pezzuto, J. M.; Cordell, G. A. Phytochemistry 2001, 56, 781-4.

(23) Saitta, M.; Giuffrida, D.; La Torre, G. L.; Potortì, A. G.; Dugo, G. Food Chem. 2009, 117, 451-455.

(24) Cui, C.; Li, C.; Cai, B.; Han, B. Preparation and Application of Cyclohexenones Bicyclic Condensed Compound. CN1733748A, 2006.

(25) Gupta, R. C. Nutraceuticals: Efficacy, Safety and Toxicity, 1st ed.; Academic Press: Cambridge, 2016.

(26) Cotelli, F.; Andronico, F.; Brivio, M.; Lamia, C. L. J. Ultrastruct. Mol. Struct. Res. 1988, 99, 70-78.

(27) McCollum, C. W.; Ducharme, N. A.; Bondesson, M.; Gustafsson, J. A. Birth Defects Res., Part C 2011, 93, 67-114.

(28) Mansour, M. P.; Holdsworth, D. G.; Forbes, S. E.; Macleod, C. K.; Volkman, J. K. Biochem. Syst. Ecol. 2005, 33, 659-674.

(29) Banzouzi, J. T.; Prado, R.; Menan, H.; Valentin, A.; Roumestan, C.; Mallie, M.; Pelissier, Y.; Blache, Y. J. Ethnopharmacol. 2002, 81, 399-401.

(30) Delemarre, B. J.; van der Kaay, H. J. Ned. Tijdschr. Geneeskd. 1979, 123, 1981.

(31) Kaneko, O. Origin of Some P. falciparum strains. http://www.m. ehime-u.ac.jp/school/parasitology/eng/Strain1.htm (accessed Jun 13, 2016).

(32) Trager, W.; Jensen, J. B. Science 1976, 193, 673-5.

(33) Bero, J.; Herent, M. F.; Schmeda-Hirschmann, G.; Frederich, M.; Quetin-Leclercq, J. J. Ethnopharmacol. 2013, 149, 176-83.

(34) Murebwayire, S.; Frederich, M.; Hannaert, V.; Jonville, M. C.; Duez, P. Phytomedicine 2008, 15, 728-33.

(35) Makler, M. T.; Ries, J. M.; Williams, J. A.; Bancroft, J. E.; Piper, R. C.; Gibbins, B. L.; Hinrichs, D. J. Am. J. Trop. Med. Hyg. 1993, 48, 739-741.

(36) Ali, S.; van Mil, H. G.; Richardson, M. K. PLoS One 2011, 6, e21076.

(37) Jansen, O.; Tits, M.; Angenot, L.; Nicolas, J. P.; De Mol, P.; Nikiema, J. B.; Frédérich, M. Malar. J. 2012, 11, 289.

(38) Frederich, M.; Jacquier, M. J.; Thepenier, P.; De Mol, P.; Tits, M.; Philippe, G.; Delaude, C.; Angenot, L.; Zeches-Hanrot, M. J. Nat. Prod. 2002, 65, 1381-6.

(39) Peters, W.; Robinson, B. L. Ann. Trop. Med. Parasitol. 1991, 85, $5-10$.

(40) Fidock, D. A.; Rosenthal, P. J.; Croft, S. L.; Brun, R.; Nwaka, S. Nat. Rev. Drug Discovery 2004, 3, 509-20. 